\title{
Magico-Religious beliefs among primary care takers of manic patients.
}

\author{
Sapkota N1, Pandey AK², Adhikari BR ${ }^{3}$, Shyangwa PMㄴ, Shakya R \\ 1.Associate Professor, Department of psychiatry BPKIHS, Dharan 2. Additional Professor, Department of \\ psychiatry, BPKIHS, Dharan 3. Assistant Professor, Department of Psychiatry, BPKIHS, Dharan 4. Professor, \\ Department of psychiatry, Dharan 5. Associate Professor, Department of Psychiatry, PAHS, Kathmandu, Nepal \\ E-mail *Corresponding author: nideshsapkota@yahoo.com
}

\begin{abstract}
Introduction: Mania is one of the commonest psychiatric disorders that require immediate interventions. There is a wide held belief that co-occurrence of mental disorders and underlying religious or spiritual problems is found. Local and community belief in such phenomena appeared to be a factor in influencing the decision to seek MagicoReligious treatment. The study was done with the objective to determine the attitudes of the primary care taker with respect to Magico-Religious beliefs which can have impact on treatment seeking behavior and timely consultation to the psychiatrist for underlying condition.
\end{abstract}

Materials and Method: Consecutive fifty primary care takers who accompanied the patient and gave consent were included in the study. The supernatural Attitude questionnaire developed to study the magico religious beliefs was applied to the primary care taker. Both parametric and non parametric statistical tools were applied to analyze the variables.

Results: About 48\% believed that performing magico-religious rituals could improve the behavior of the patients and $76 \%$ of the primary caretakers visited faith healer for this purpose. Association between Magico-religious treatment group and non-magico-religious treatment group with different variables like Age, Sex, Religion, SocioEconomic Status, Education and Occupation, were compared, which shows that, all the variables were comparable and the P-value was not significant.

Conclusion: There is a common belief among the primary care takers about the relationship between supernatural's influences and mental illness. The study concluded that there exists no significant relationship between socio demographic characteristics of a primary care takers and traditional practices and beliefs and hence are independent of each other.

Key words: Magico-religious belief, primary care takers, manic patients.

\section{INTRODUCTION}

Mania is one of the commonest psychiatric disorders which require immediate intervention as it causes severe social, occupational disturbances even occasionally life threatening consequences ${ }^{1}$.The lifetime risk for developing bipolar mania is around $1 \%(0.4-1.6 \%)^{2}$ and recurrence is almost $90 \%$.
Unlike the other branches of medicine, a psychiatrist must depend upon the clinical interviews and observations for making a diagnosis and monitoring its course. There is a wide held belief that co-occurrence of mental disorders and underlying religious or spiritual problems is found and manic psychosis is no exception. Ascribing illness to external 
malevolent influences e.g. spirits, Gods, deities is common notion and is shared by practically all the so-called primitive or non-literate societies and even modern industrialized societies also subscribe to this view to different degrees, indicating that cultural background strongly influences the symptoms of mental illness ${ }^{3}$. Mental illness is seen as related to life stresses, social or family conflicts and evil spirits $^{3}$. Local and community belief in such phenomena appeared to be a factor in influencing the decision to seek MagicoReligious treatment.

The term Magico-Religious is commonly used to describe beliefs prevalent in a particular culture concerning various supernatural influences operating in the environment. The treatment by an indigenous healer is considered to be brought about by such influences, which is known as Magico Religious treatment ${ }^{4}$. In Indian subcontinent Magico-Religious beliefs are frequently conjectured as causal explanations of mental illnesses, and consequently services of "faith healers" are often sought for treatment of mental disorders 5,6. In our culture also we frequently see such beliefs and primary care takers take the help of faith healers and other religious treatment. So this study was done with the aim to determine the attitudes of the primary care taker with respect to MagicoReligious beliefs which can have impact on treatment seeking behavior and timely consultation to the psychiatrist for underlying condition.

\section{METHOD AND MATERIAL}

This is a descriptive cross sectional study conducted in B.P. Koirala Institute of Health and Science. It is a tertiary level, referral health institute in eastern Nepal. The psychiatry department has both inpatient and outdoor facilities. It also runs the communities out-reach clinics at four rural settings. Fifty consecutive subjects here by referred as primary care taker (operational definition of Primary care taker: significant person who is related to patient and staying with the patient and are actively involved in his or her care) whose patients were admitted in the psychiatric ward were included in the study. The informed consent was obtained and the process was explained to all the participants. Those who refused to take part in the study were not included. Epidemiological indices were noted down with regard to age, sex, ethnicity, occupation, education and geographical areas using a structured Performa. The supernatural Attitude questionnaire 4 developed to study the magico religious beliefs were translated in Nepali language and back translated in English by the expert in related language. In this study the Nepali version of the questionnaire was applied to the primary care taker. Both parametric and non parametric statistical tools were applied to analyse the variables.

\section{RESULT}

\section{Demographic variables}

Of the 50 primary care takers, $26 \%$ were spouses of the patients, $50 \%$ were parents, $22 \%$ were siblings of the patients, and the remaining $2 \%$ were son. The mean age of the samples was 41.67 (SD 8.30) years and 34\% of them belonged to age group 50-59.Seventy percent of the primary care takers were male and $82 \%$ were Hindu. Only $14 \%$ of them had 10 years or more of formal school education, whereas $24 \%$ of them were illiterate. Among them 42\% were farmers by occupations. All the relatives comprehended the supernatural Attitude Questionnaire quite easily.

Figure 1: Age wise characteristics of the Primary Care takers

a Percentage (\%)

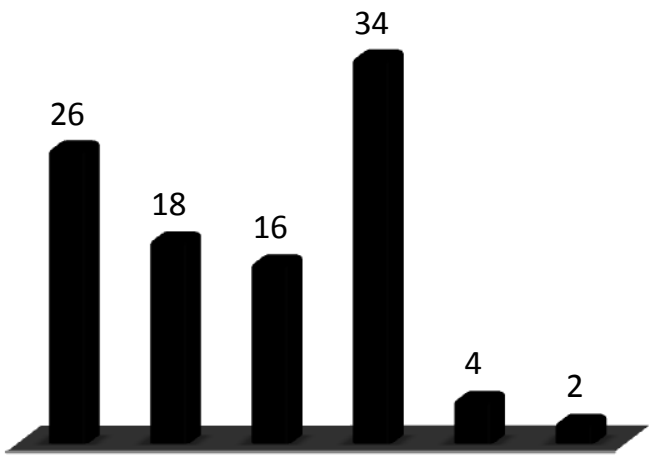


Figure 2: Sex of the Primary Care takers

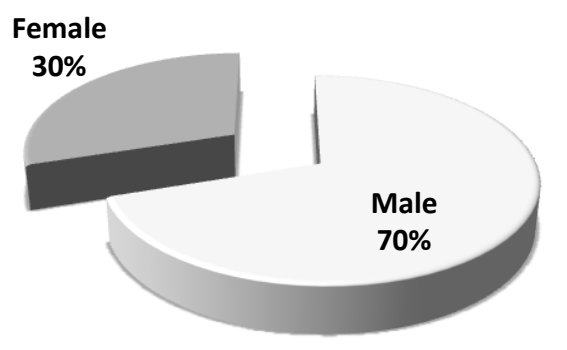

Figure 3: Religious Characteristics of the Primary Care takers

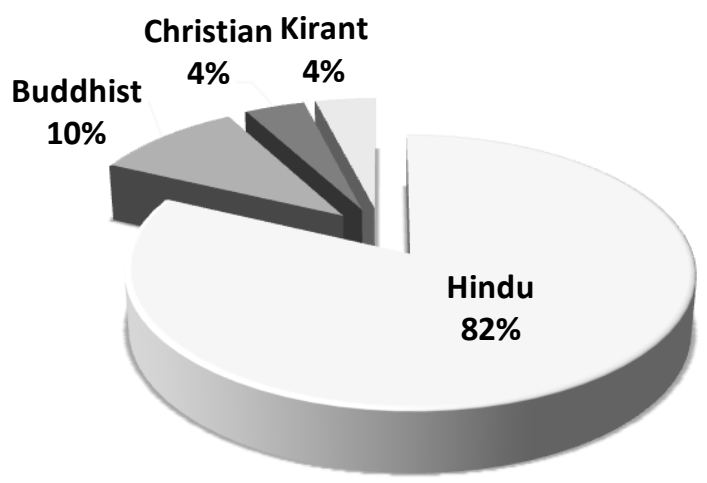

Figure 4: Educational Characteristics of the Primary Care takers

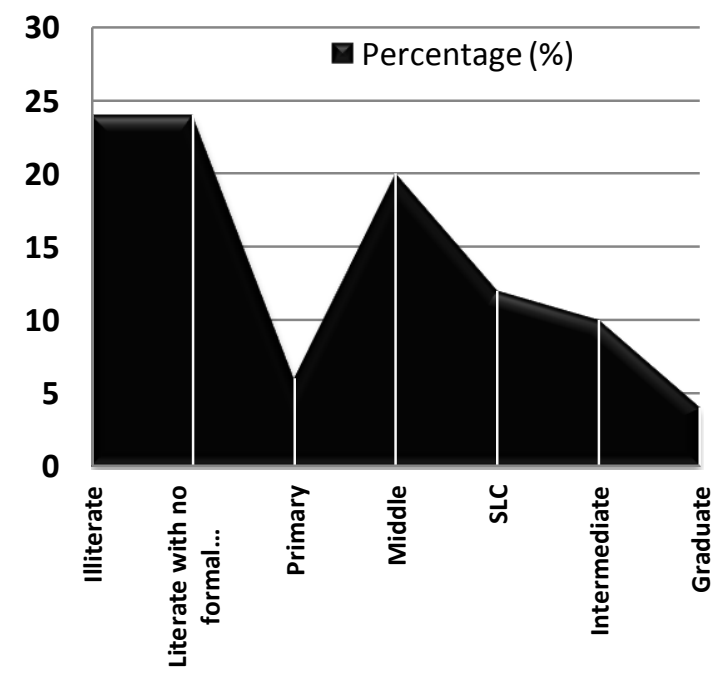

Figure 5: Occupational Characteristics of the Primary Care takers

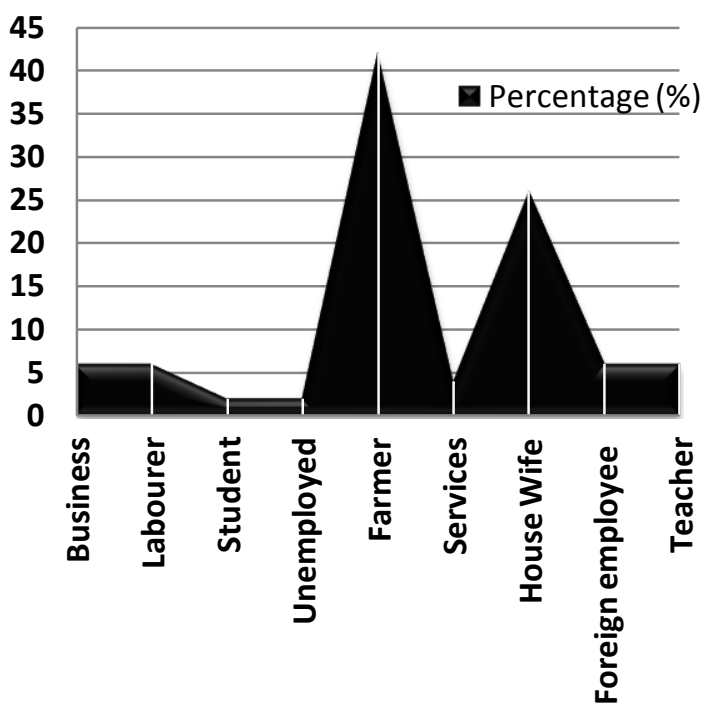

\section{Supernatural Attitude Questionnaire}

When the primary care takers were questioned, $44 \%$ of them acknowledged personal belief in Jadu Tona (Sorcery), 58\% in Bhoot Pret (ghosts/evil spirits) and $52 \%$ in Pret Aatma (Spirit intrusion). When the question was asked about the role of such influences in causing mental illness, $42 \%$ of them had belief in the causative power/link between sorcery \& mental illness, $26 \%$ of them believed that ghosts/evil spirits caused mental illness and $32 \%$ of the primary care taker held that spirit intrusion caused such illness. About $40 \%$ of them were of the opinion that divine wrath (Devi Devta Prakop) can cause mental illness, $52 \%$ of the relatives felt that planetary/astrological influences (GrahNakchatra) can cause mental illness, $28 \%$ of them believed that dissatisfied or evil spirit can cause mental illness and 38\% were convinced that retribution for bad deeds in the past (Karma) could result in mental illness.

Regarding the link between the abnormal behavior of the patients and these supernatural influences, it was revealed that $34 \%$ of them attributed the display of abnormal behavior by the patient to sorcery, $32 \%$ to ghosts/ evil spirits, $18 \%$ to spirit intrusion and $28 \%$ each to divine wrath, planetary influences and dissatisfied/ evil spirits. 
Table 1: Response of the Primary Care takers

\section{Frequency Percentage}

Do you believe in (n) $\quad(\%)$ sorcery/witchcraft?

\begin{tabular}{|c|c|c|}
\hline Yes & 22 & 44.0 \\
\hline No & 28 & 56.0 \\
\hline Total & 50 & 100.0 \\
\hline \multicolumn{3}{|c|}{ Do you believe in Ghosts/Evil Spirits? } \\
\hline Yes & 29 & 58.0 \\
\hline No & 21 & 42.0 \\
\hline Total & 50 & 100.0 \\
\hline \multicolumn{3}{|c|}{ Do you believe in Spirit Intrusion? } \\
\hline Yes & 26 & 52.0 \\
\hline No & 24 & 48.0 \\
\hline Total & 50 & 100.0 \\
\hline \multicolumn{3}{|c|}{$\begin{array}{l}\text { Do you think sorcery/Witch Craft can cause } \\
\text { mental illness? }\end{array}$} \\
\hline Yes & 21 & 42.0 \\
\hline No & 29 & 58.0 \\
\hline Total & 50 & 100.0 \\
\hline \multicolumn{3}{|c|}{$\begin{array}{l}\text { Do you think Ghosts/Evil Spirits can cause } \\
\text { mental illness? }\end{array}$} \\
\hline Yes & 13 & 26.0 \\
\hline No & 37 & 74.0 \\
\hline Total & 50 & 100.0 \\
\hline \multicolumn{3}{|c|}{$\begin{array}{l}\text { Do you think spirit intrusion can cause mental } \\
\text { illness }\end{array}$} \\
\hline Yes & 16 & 32.0 \\
\hline No & 34 & 68.0 \\
\hline Total & 50 & 100.0 \\
\hline
\end{tabular}

Do you think Divine Wrath can cause mental illness?

\begin{tabular}{lll}
\hline Yes & 20 & 40.0 \\
No & 30 & 60.0 \\
\hline Total & $\mathbf{5 0}$ & $\mathbf{1 0 0 . 0}$ \\
\hline
\end{tabular}

Do you think adverse planetary/Astrological influences can cause mental illness?

\begin{tabular}{|c|c|c|}
\hline Yes & 26 & 52.0 \\
\hline No & 24 & 48.0 \\
\hline Total & 50 & 100.0 \\
\hline \multicolumn{3}{|c|}{$\begin{array}{l}\text { Do you think dissatisfied or evil spirit can } \\
\text { cause mental illness? }\end{array}$} \\
\hline Yes & 14 & 28.0 \\
\hline No & 36 & 72.0 \\
\hline Total & 50 & 100.0 \\
\hline \multicolumn{3}{|c|}{$\begin{array}{l}\text { Do you think that mental illness is as } \\
\text { retribution of a bad deed in previous life? }\end{array}$} \\
\hline Yes & 19 & 38.0 \\
\hline No & 31 & 62.0 \\
\hline Total & 50 & 100.0 \\
\hline
\end{tabular}

Table 2: Behavioral Characteristics of the respondents

Do you think patient's behaviour is due to:

\begin{tabular}{lll} 
Sorcery/Witchcraft & $\begin{array}{l}\text { Frequency } \\
\text { (n) }\end{array}$ & $\begin{array}{l}\text { Percentage } \\
\text { (\%) }\end{array}$ \\
\hline Yes & 17 & 34.0 \\
No & 33 & 66.0 \\
\hline Total & 50 & 100.0 \\
\hline Ghost/Evil Spirits & & \\
\hline Yes & 16 & 32.0 \\
No & 34 & 68.0 \\
\hline Total & 50 & 100.0 \\
\hline Spirit Intrusion & & \\
\hline Yes & 9 & 18.0 \\
No & 41 & 82.0 \\
\hline Total & 50 & 100.0 \\
\hline Divine Wrath & & \\
\hline Yes & 14 & 28.0 \\
No & 36 & 72.0 \\
\hline Total & 50 & 100.0 \\
\hline Planetary Influences & \\
\hline Yes & 24 & 48.0 \\
No & 26 & 52.0 \\
\hline Total & 50 & 100.0 \\
\hline Evil Spirits & \\
\hline Yes & 13 & 26.0 \\
No & 37 & 74.0 \\
\hline Total & 50 & 100.0 \\
\hline
\end{tabular}

Regarding the beliefs of primary care taker and patients in various supernatural phenomena, it was seen that most of them had an admixture of two or more than such beliefs. The finding shows though the majority of the primary care taker claimed not to believe in such influences and link with the mental disorder but magicoreligious treatment was sought by them for the patients. 
Table 3: Behavioral characteristics of the respondents with regards to rituals

Do you think Puja/Rituals/ Jhad-phoonk can change behaviour?

\begin{tabular}{lll} 
& Frequency $(\mathbf{n})$ & Percentage $\mathbf{( \% )}$ \\
\hline Yes & 24 & 48.0 \\
No & 26 & 52.0 \\
\hline Total & 50 & 100.0 \\
\hline \multicolumn{2}{l}{ Did you consult a faith healer? } \\
\hline Yes & 38 & 76.0 \\
No & 12 & 24.0 \\
\hline Total & 50 & 100.0 \\
\hline Was & Puja/Ritual/Jhad-phoonk & performed \\
with a view of & making better? \\
\hline Yes & 35 & 70.0 \\
No & 15 & 30.0 \\
\hline Total & 50 & 100.0
\end{tabular}

Table 4: Belief characteristics of the respondents

Does the patient believe or talk about:

Sorcery/Witch Frequency (n) Percentage craft

\begin{tabular}{lll} 
craft & & $(\%)$ \\
Yes & 19 & 38.0 \\
No & 31 & 62.0 \\
\hline Total & 50 & 100.0 \\
\hline \multicolumn{2}{l}{ Ghosts/Evil Spirits } & \\
\hline Yes & 17 & 34.0 \\
No & 33 & 66.0 \\
\hline Total & 50 & 100.0 \\
\hline Spirit Intrusion & \\
\hline Yes & 11 & 22.0 \\
No & 39 & 78.0 \\
\hline Total & 50 & 100.0 \\
\hline Divine Wroth & & \\
\hline Yes & 16 & 32.0 \\
No & 34 & 68.0 \\
\hline Total & 50 & 100.0 \\
\hline Planetary & Influences & \\
\hline Yes & 7 & 14.0 \\
No & 43 & 86.0 \\
\hline Total & 50 & 100.0 \\
\hline Evil Spirit & & \\
\hline Yes & 22 & 44.0 \\
No & 28 & 56.0 \\
\hline Total & 50 & 100.0 \\
\hline & &
\end{tabular}

Did he talk or believe in these things before falling ill ?

\begin{tabular}{lll}
\hline Yes & 6 & 12.0 \\
No & 44 & 88.0 \\
\hline Total & 50 & 100.0
\end{tabular}

\begin{tabular}{lcc}
\hline $\begin{array}{l}\text { Did patients } \\
\text { request }\end{array}$ & visit & faith healer at his/her \\
\hline Yes & 24 & 48.0 \\
No & 26 & 52.0 \\
\hline Total & 50 & 100.0 \\
\hline Community believes in such influences? \\
\hline Yes & 40 & 80.0 \\
No & 10 & 20.0 \\
\hline Total & 50 & 100.0 \\
\hline Does the patient belong to & specific religious \\
sect? & & \\
\hline Yes & 5 & 10.0 \\
No & 45 & 90.0 \\
\hline Total & 50 & 100.0
\end{tabular}

Table 5: Association between magico-religious treatment group and non magico-religious treatment group with different variables

$\begin{array}{llll}\text { Variables } & \text { Magic } & \text { Non } & P \text { - } \\ & \text { o- } & \text { magico } & \text { value } \\ & \text { religi } & - & \\ & \text { ous } t / t & \text { religio } & \end{array}$
group us $t / t$

\begin{tabular}{|c|c|c|c|c|}
\hline & & & grou & \\
\hline \multirow[b]{2}{*}{ Age } & $<40 \mathrm{Yrs}$ & $36 \%$ & $8 \%$ & \multirow{2}{*}{$\begin{array}{l}0.304 \\
*\end{array}$} \\
\hline & $\geq 40 \mathrm{Yrs}$ & $40 \%$ & $16 \%$ & \\
\hline \multirow[t]{2}{*}{ Sex } & Male & $56 \%$ & $14 \%$ & \multirow{2}{*}{$\begin{array}{l}0.254 \\
*\end{array}$} \\
\hline & Female & $20 \%$ & $5 \%$ & \\
\hline \multirow[t]{2}{*}{ Religion } & Hindus & $64 \%$ & $18 \%$ & \multirow{2}{*}{$\begin{array}{l}0.368 \\
*\end{array}$} \\
\hline & Others & $12 \%$ & $6 \%$ & \\
\hline \multirow{2}{*}{$\begin{array}{l}\text { socio- } \\
\text { economic } \\
\text { status }\end{array}$} & Low & $44 \%$ & $12 \%$ & \multirow{2}{*}{$\begin{array}{l}0.503 \\
*\end{array}$} \\
\hline & Middle & $34 \%$ & $12 \%$ & \\
\hline \multirow[t]{2}{*}{ Education } & Illiterate & $18 \%$ & $6 \%$ & \multirow{2}{*}{$\begin{array}{l}0.304 \\
*\end{array}$} \\
\hline & Literate & $58 \%$ & $18 \%$ & \\
\hline \multirow[t]{2}{*}{ Occupation } & $\begin{array}{l}\text { Professi } \\
\text { onal }\end{array}$ & $12 \%$ & $8 \%$ & \multirow[t]{2}{*}{$\begin{array}{l}0.179 \\
*\end{array}$} \\
\hline & $\begin{array}{l}\text { Non- } \\
\text { professi } \\
\text { onal }\end{array}$ & $64 \%$ & $16 \%$ & \\
\hline
\end{tabular}


Association between Magico-religious treatment group and non-magico-religious treatment group with different variables like Age, Sex, Religion, Socio-Economic Status, Education and Occupation, were compared, as shown in the table, which shows that, all the variables were comparable and the P-value was not significant hence indicating that the socio demographic variable are independent of magico religious treatment.

\section{DISCUSSION}

In view of the sparse research in this and the related field of magico-religious beliefs it is pertinent here to discuss findings of this study and the findings obtained from various other studies. There are few studies carried out in India in which attitudes towards supernatural influences and their role in causing mental illness have been studied. Studies by Chakraborthy and Bhattacharya 7 , Prabhu 8 and Verghese and Beig ${ }^{9}$, have shown that the general population, including subjects from the urban background believed that supernatural influences like demonology and black magic can cause mental illness. In the study done by Kulhara et $\mathrm{al}^{4}$, it was found that in about $40 \%$ of the cases, the key relatives believed that behavioural abnormalities in the patients could be caused by various types of supernatural influences.

In the study $31 \%$ of the primary care takers believed that it could be due to such influences. Similarly, other studies have been carried out to find out influences of magico-religious belief in various mental disorders. Malhotra and Wig10 observed that in $2 \%$ of the cases faith healing was preferred. Whereas Boral et al11, found that in severe mental disorders other treatment modalities like electro convulsive therapy or medicines were preferred. In the study done by Kulhara et $\mathrm{al}^{4}$, nearly $33 \%$ of the cases, relatives thought that magico-religious treatment could improve the patient's conditions, while $58 \%$ of the cases actually carried out. In the same study major portion of the study population believed that supernatural influences could cause severe mental illness and magico-religious treatment was sought in the majority of the cases.
In our study the main reasons for seeking magico-religious treatment could not be pointed out for single reason. In fact there are many factors primarily; it is the patient's belief in such influences, belief of the relatives in such supernatural influences and belief of the neighborhood. Interestingly, it was observed that majority of the primary care takers though did not believe in such supernatural influences but magico-religious treatment was sought. It is likely that magico-religious treatment was sought because of social pressure to do so. Magico-religious treatment when sought by either personal choice or as a result of social pressure often delays or hinders initiation of psychiatric treatment. In few of the cases it was observed that psychiatric treatment was discontinued and patient was subjected to magico-religious treatment on faith healer's advice, which may harm the patient in a great deal. So, this issue should be included in psycho-education.

Seeking Magico-religious treatment was speculated to be associated with low educational background, rural set-up, female sex and neurotic illnesses like hysteria and somatoform disorders ${ }^{4}$. This was not applicable in this study, as both the groups i.e. Magico-religious treatment and Non magico-religious treatment were comparable on the variables stated above. In fact, a majority of the primary care takers had adequate educational background (more than 10 years of formal education).

Similar kind of study was conducted by Kulhara et $\mathrm{al}^{4}$ in Schizophrenic patients, where similar finding / results were yielded. In this part of the world, family members including relatives and neighbour have considerable influence on the patient care and choice of treatment. At the same time, due to the nature of illness patient is unaware about the illness and is unable to decide about the treatment. Their belief in supernatural influences could be one of the reasons in seeking magico-religious treatment irrespective of their socio-economic status and educational background. There could be other reasons, as the modern medical services are not widely available and lack of awareness 
regarding those services where they are available.

\section{CONCLUSION}

The study concluded that there exists no significant relationship between socio demographic characteristics of a primary care takers and traditional practices and beliefs and hence are independent of each other.

\section{REFERENCE}

1. World Health Organization, International Classification of diseases 10, DCR, 1993.

2. Weissman MM, Bland RC, Canino GJ, et al. Cross- National Epidemiology of Major Depression and Bipolar disorder. The Journal of the American Medical Association.1996; 276(4):293-299.

3. Goodwin F, Jamison K. Manic depressive illness. New York, Oxford University Press. 1990: 302.

4. Kulhara P, Avasthi A, Sharma A.Magico-Religious Beliefs in Schizophrenia:A study from North India. Psychopathology 2000 MarchApril; 33(2): 62-68.

5. Spiro ME. The psychological function of witchcraft belief: The Burmese care, in Candill W, Lin T (eds): Mental Health Research in Asia and Pacific. Honolulu East West Center Press, 1969.

6. Chakraborty A. An Analysis of paranoid symptomatology Indian J of Psychiatry. 1964;6:172-184

7. Chakraborty A, Bhattacharya D: Witchcraft beliefs and persecutory ideas in Bengali Culture. Indian J Soc Psychiatry. 1985;1:231-243

8. Prabhu GG: Mental illness, Public attitudes and Public education. Indian J clin Psychol. 1983; 10:13-26.

9. Varghese A, \& Beig A. (1974). Public Attitudes towards Mental Illness- The Velore study. Indian Journal of Psychiatry. 16, 8-18.

10. Malhotra H, Wig NN. How does the public manage deviant behaviour? Indian J Psychiatry 1975; 13: 95-98.
11. Boral GC, Bagehi R, Nand DN. An opinion survey about the causes and treatment of mental illness and the social acceptance of the mentally ill people, Indian J Psychiatry. 1980; 22: 235-238. 